\title{
Effects of Deep Cryogenic Treatment on the Microstructure and Properties of Rolled Cu Foil
}

\author{
Zhichao Dong, Xiangyu Fei * ${ }^{\mathbb{D}}$, Benkui Gong *, Xinyu Zhao and Jiwei Nie \\ School of Materials Science and Engineering, Shandong University of Technology, Zibo 255049, China; \\ ZCDOng@sdut.edu.cn (Z.D.); zhaoxinyu@sdut.edu.cn (X.Z.); niejiwei789@163.com (J.N.) \\ * Correspondence: xy_fey@yeah.net (X.F.); 3120160015@bit.edu.cn (B.G.); Tel.: +86-133-8645-4775 (X.F.)
}

check for updates

Citation: Dong, Z.; Fei, X.; Gong, B.; Zhao, X.; Nie, J. Effects of Deep Cryogenic Treatment on the Microstructure and Properties of Rolled Cu Foil. Materials 2021, 14 , 5498. https://doi.org/10.3390/ ma14195498

Academic Editor: Daniel de la Fuente

Received: 30 August 2021

Accepted: 21 September 2021

Published: 23 September 2021

Publisher's Note: MDPI stays neutral with regard to jurisdictional claims in published maps and institutional affiliations.

Copyright: (C) 2021 by the authors. Licensee MDPI, Basel, Switzerland. This article is an open access article distributed under the terms and conditions of the Creative Commons Attribution (CC BY) license (https:/ / creativecommons.org/licenses/by/ $4.0 /)$.
Abstract: The development of fifth-generation (5G) communication and wearable electronics generates higher requirements for the mechanical properties of copper foil. Higher mechanical properties and lower resistance are required for flexible copper-clad laminate and high-frequency and highspeed Cu foil. Deep cryogenic treatment (DCT), as a post-treatment method, has many advantages, such as low cost and ease of operation. However, less attention has been paid to the impact of DCT on rolled $\mathrm{Cu}$ foil. In this study, the effects of DCT on the microstructure and mechanical properties of rolled $\mathrm{Cu}$ foil were investigated. The results show that as the treatment time increased, the tensile strength and hardness first increased and then decreased, reaching a peak value of $394.06 \mathrm{MPa}$ and $1.47 \mathrm{GPa}$ at $12 \mathrm{~h}$. The mechanical property improvement of rolled $\mathrm{Cu}$ foil was due to the grain refinement and the increase of dislocation density. The dislocation density of rolled $\mathrm{Cu}$ foil after a DCT time of $12 \mathrm{~h}$ was determined to have a peak value of $4.3798 \times 10^{15} \mathrm{~m}^{-2}$. The dislocation density increased by $19 \%$ and the grain size decreased by $12 \%$ after $12 \mathrm{~h}$ DCT.

Keywords: rolled Cu foil; deep cryogenic treatment; microstructure; mechanical properties; corrosion resistance

\section{Introduction}

Rolled copper $(\mathrm{Cu})$ foil is widely used in various fields such as communication [1], energy [2,3], and transportation [4] due to its excellent conductivity, ductility, electromagnetic shielding, and corrosion resistance. In addition, it has been used as a main component in copper-clad laminate (CCL) and lithium-ion batteries (LIBs) [5-7]. Advanced mechanical properties of $\mathrm{Cu}$ foil are required to adapt to the development of 5G communication [8], wearable electronics [9], and new energy vehicles (NEV) $[10,11]$. To date, various methods, such as ultrasonic surface rolling processing (USRP) [12], ultrasonic peening technique [13], and electrophoretic deposition (EPD) [14], have been applied to enhance the conductivity and corrosion resistance of $\mathrm{Cu}$ foil. However, the costly equipment and complex operations involved in these methods limit their practical applications.

Deep cryogenic treatment (DCT) refers to a process in which materials are treated at a temperature below $-130{ }^{\circ} \mathrm{C}$ using liquid nitrogen (LN2) as a refrigerant. The DCT technique has been extensively used for ferrous and non-ferrous metals due to its ease of operation and low cost. DCT can refine the microstructure and inner stress of materials, which improves the mechanical behavior of the treated materials [15,16]. Liu et al. [17] investigated the mechanical properties and organizational structure evolution of a $\mathrm{Cu}$ plate after depositing $\mathrm{Cu}$-rich $\mathrm{Cu}$-Al-Si alloy using the cold metal transfer (CMT) technique. In addition, DCT can refine the size of grains and randomize the texture to improve the microhardness and tensile strength. Jovičević-Klug et al. [18] explored the effects of DCT on the surface chemistry and phase transformation of high-speed steels. Compared to the conventional heat treatment (CHT), DCT positively impacted the microstructure, making martensitic laths become sharper, smaller, and more oriented. Despite this progress, the effects of DCT on the surface chemistry of treated materials are still unclear. Dong et al. [19] 
found that the dislocation density of Al-Cu-Mn alloy significantly increased after DCT. Moreover, the tensile and yield strengths and elongations were promoted because of the grain refinement. Funk et al. [20] reported that DCT promotes the transformation of retained austenite while, at the same time, decreased electrical resistivity, Young's modulus, and yield limit were observed due to the transformation of retained austenite. $\mathrm{Li}$ et al. [21] found that the rolling process at cryogenic temperature could induce the unique transformation of the microstructure. The ultra-low temperature restrains the atomic motion and dislocation slip, causing the kinking of grains and mechanical twinning. Lv et al. [22] investigated the effects of DCT on the mechanical behavior of bulk metallic glass. The samples exhibited a lower pop-in force and hardness after DCT because the densifiction of shear bands was promoted [23]. Yuan et al. [24] studied the drawability of aluminum alloy sheets treated by DCT at different temperatures. The deep drawability was improved as the temperature decreased. The cup drawn at ultra-low temperatures exhibited uniform thickness distribution and significant drawing height and load. Barylski et al. [25] investigated the effects of DCT on the wear and mechanical properties of Mg-Y$\mathrm{Nd}-\mathrm{Zr}$ alloy. It was found that the reduction of defects (dislocations and stacking faults) caused by DCT jeopardized the mechanical properties of the alloy, which can be improved by the aging process. Although extensive investigations of DCT have been conducted for many metals, there are fewer reports of DCT in the field of ultra-thin $\mathrm{Cu}$ foil. So, it is crucial to analyze the effects of DCT on $\mathrm{Cu}$ foil.

In this paper, the effects of DCT on the microstructure, mechanical, physical, and chemical properties of rolled $\mathrm{Cu}$ foil are studied. The results show that DCT significantly improved the tensile strength and nano-hardness of rolled $\mathrm{Cu}$ foil. The mechanism of mechanical properties improvement is proposed by investigating the microstructure, corrosion resistance, and dislocation density.

\section{Materials and Methods}

In this study, $12 \mu \mathrm{m}$ Cu foils (Shandong Tianhe Rolled Copper Foil Co., Ltd., Heze, China, Ag < 100 ppm) were processed by DCT in LN2 for different times. Specifically, the $\mathrm{Cu}$ foils were soaked in LN2 at $88 \mathrm{~K}$ for $0 \mathrm{~h}, 12 \mathrm{~h}, 24 \mathrm{~h}$, and $48 \mathrm{~h}$, which corresponds to DCTCu-0, DCTCu-12, DCTCu-24, and DCTCu-48, respectively.

The morphology and crystal orientation of $\mathrm{Cu}$ foil were investigated using a field emission scanning electron microscope (FE-SEM Apero S, FEI, Waltham, MA, USA) equipped with an electron backscatter diffraction (EBSD) system. The samples were processed by the hybrid ion milling system (IM4000, Hitachi, Tokyo, Japan) for surface observation and EBSD analysis. The applied parameters for ion milling are shown in Table 1.

Table 1. The parameters for ion milling.

\begin{tabular}{cc}
\hline Parameter & Value \\
\hline Discharge voltage $/ \mathrm{kV}$ & 1.5 \\
Acceleration voltage $/ \mathrm{kV}$ & 4 \\
Ion beam irradiation angle $/{ }^{\circ}$ & 80 \\
Specimen rotation speed $/ \mathrm{r} \mathrm{min}$ & -1 \\
Ar gas flow $/ \mathrm{cm}^{3} \mathrm{~min}^{-1}$ & 25 \\
\hline
\end{tabular}

The crystal lattice of $\mathrm{Cu}$ foils was characterized using a high-resolution transmission electron microscope (HRTEM, Tecnai G2F 20, FEI, Waltham, MA, USA). The Cu foils were punched into $3 \mathrm{~mm}$ diameter foils. Subsequently, the thin TEM foils were thinned by ion milling using an argon ion mill (Gatan Pips II 695, Gatan, Pleasanton, CA, USA) at 4 kV.

The uniaxial tensile performance was evaluated by a universal machine (5967-E2, Instron, MA, USA) at room temperature with a crosshead speed of $1.0 \mathrm{~mm} \mathrm{~min}^{-1}$. The axial displacement was measured by an auto-extensometer (AutoX750, Instron, MA, USA). Each sample was measured three times. 
The load-displacement curves, nano-hardness, and elastic modulus were characterized by a nano-indentation machine (Nanotest Vantage Alpha, Micro Materials, Wrexham, UK), with a standard Berkovich diamond indenter indentation depth of $500 \mathrm{~nm}$.

The corrosion resistance was quantified by the Tafel test and A.C. impedance methods. The three-electrode system was used to examine the corrosion of $\mathrm{Cu}$ foil in a solution of 3.5 wt. \%. sodium chloride $(\mathrm{NaCl})$, which was degassed by purging with nitrogen for $20 \mathrm{~min}$. The $\mathrm{Cu}$ foil was used as the working electrode, the platinum (Pt) plate was applied as a counter electrode, and the saturated calomel electrode (SCE) was utilized as a reference electrode. The Tafel curves were obtained using an electrochemical workstation (CHI760E, CHI Instrument, Shanghai, China), with the initial potential at open circle potential $(\mathrm{OCP})$ plus $0.6 \mathrm{~V}$, the final potential at OCP minus $0.6 \mathrm{~V}$, and the scan rate at $0.01 \mathrm{~V} \mathrm{~s}^{-1}$, and electrochemical impedance spectroscopy (EIS) in a frequency range from $0.01 \mathrm{~Hz}$ to $100 \mathrm{kHz}$ at open circle potential.

The grain size and dislocation density of the $\mathrm{Cu}$ foil were determined using $\mathrm{X}$-ray diffraction (D8 Advance, Bruker AXS, Karlsruhe, Germany) with $\mathrm{Cu} \mathrm{K} \alpha$ radiation (wavelength $\lambda=1.54 \AA$ ) at $35 \mathrm{kV}$ and $30 \mathrm{~mA}$. The scanning range, rate, and step size were $30^{\circ}-100^{\circ}, 2^{\circ} / \mathrm{min}$, and $0.02^{\circ}$, respectively.

\section{Results and Discussion}

\subsection{Mechanical Properties}

The mechanical properties of $\mathrm{Cu}$ foils processed by DCT for various times were characterized (Figures 1 and 2). The stress-strain curves of $\mathrm{Cu}$ foils at DCT time, $0 \mathrm{~h}$ (DCT-0), 12 h (DCT-12), 24 h (DCT-24), and 48 h (DCT-48) are depicted in Figure 1a-d. The tensile strength and elongation first increased and then decreased with the increase in DCT time, peaking at $394.06 \mathrm{MPa}$ and $0.761 \%$ at the DCT time of $12 \mathrm{~h}$ (Figure 1e). The real-time operation of the universal machine and nano-indentation during measurement are depicted in Figures $1 \mathrm{f}$ and $2 \mathrm{f}$, respectively. The nano-hardness of $\mathrm{Cu}$ foil samples after DCT for different times is shown in Figure 2. The hardness and elastic modulus reached the maximum value of $1.47 \mathrm{GPa}$ and $61.34 \mathrm{GPa}$ at the DCT time of $12 \mathrm{~h}$. The nano-hardness of DCT-0, DCT-24, and DCT-24 were $1.340 \mathrm{GPa}, 0.519 \mathrm{GPa}$, and $0.251 \mathrm{GPa}$, respectively. The uniaxial tensile strength and nano-hardness exhibited a similar trend under DCT, whereby they first increased then decreased with an increase in DCT time.

\subsection{Corrosion Resistance}

To assess the corrosion resistance of the $\mathrm{Cu}$ foil for different DCT times, the electrochemical properties were tested (Figure 3). Figure 3a shows the potentiodynamic polarization curves. The linear-fitting results of the anode and cathode areas of the $\mathrm{Cu}$ foil at various DCT times were calculated (Figure $3 \mathrm{~d}$ ). The corrosion resistance measured by the Tafel extrapolation method exhibited a high self-corrosive current $\left(2.932 \times 10^{-5} \mathrm{~A} \mathrm{~cm}^{-2}\right)$, which indicates that the sample of DCT-12 had poor corrosion resistance. 

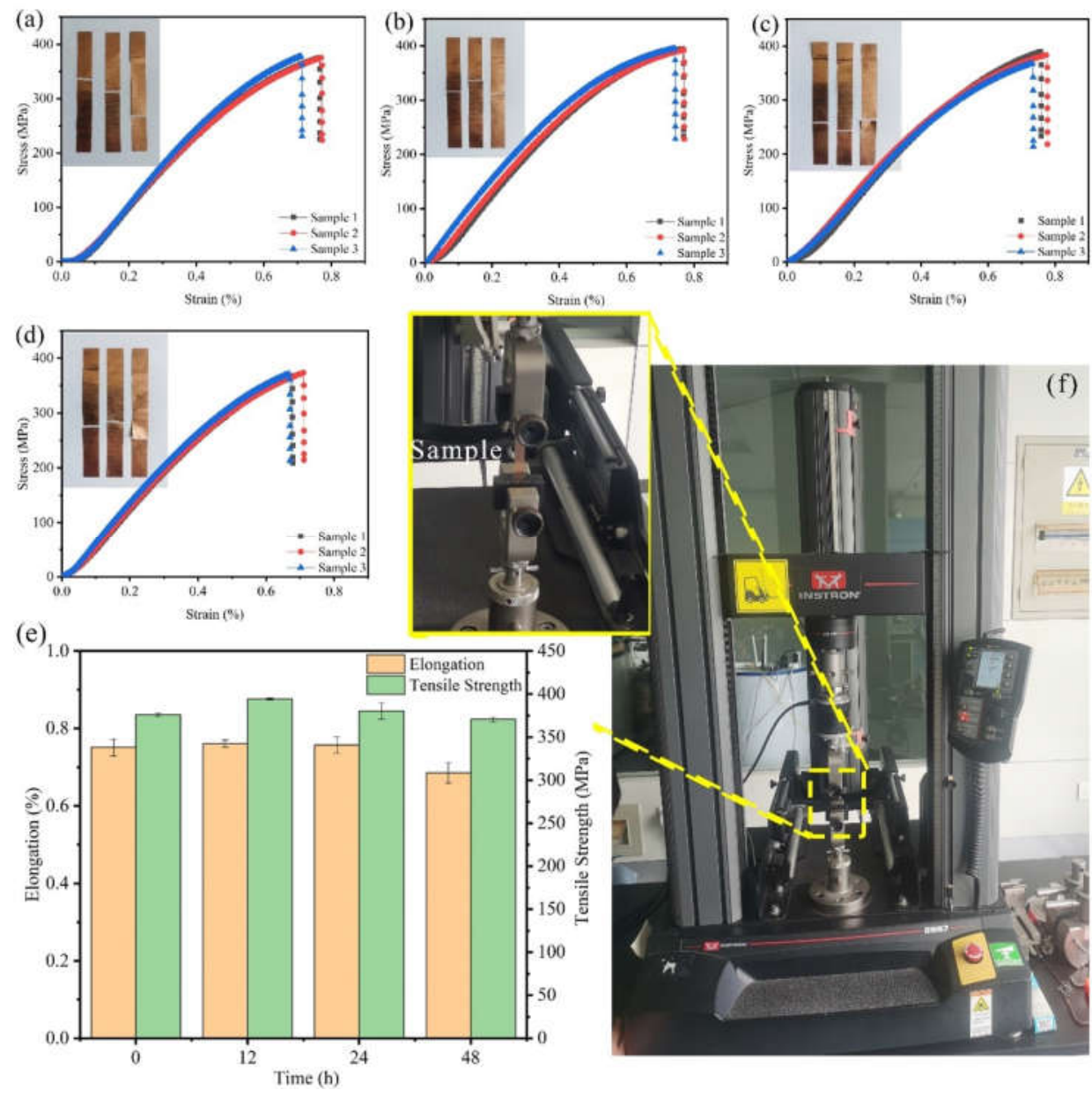

Figure 1. Stress-strain curves and images of $\mathrm{Cu}$ foils treated by DCT for (a) $0 \mathrm{~h} \mathrm{(b)} 12 \mathrm{~h}$, (c) $24 \mathrm{~h}$, and (d) $48 \mathrm{~h}$, (e) effects of DCT time on the uniaxial tensile performance, (f) a picture of the universal machine.

The EIS curve is depicted in Figure 3b. The ohmic resistance between the electrolyte and electrode is described by the intersection of the semicircle and the real axis in the high frequency region [26]. The charged electron transfer resistance is depicted by the slope of the line in the middle frequency region [27]. The curves illustrate that the DCT-12 had better electrochemical performance than the others. The former had lower charge transfer resistance and better conductivity [28], leading to a faster electron transfer speed. The EIS spectrum is also consistent with the results of the Tafel curve. The electrical equivalent circuit model and the corresponding data obtained from the equivalent circuit model are shown in Figure $3 c, d$. The $R_{s}$ is the resistance of electrolyte. The $R_{t}$ and $R_{f}$ are the outer resistance of the electrochemical system and the resistance of the inner layer that covers the metal surface $[29,30]$. The passivation film formed on the $\mathrm{Cu}$ foil in the corrosive environment had better corrosion resistance at DCT-48 $\left(3020 \Omega \mathrm{cm}^{-2}\right)$. The corrosion resistance of $\mathrm{Cu}$ foils first increased then decreased with the increase in DCT time. 

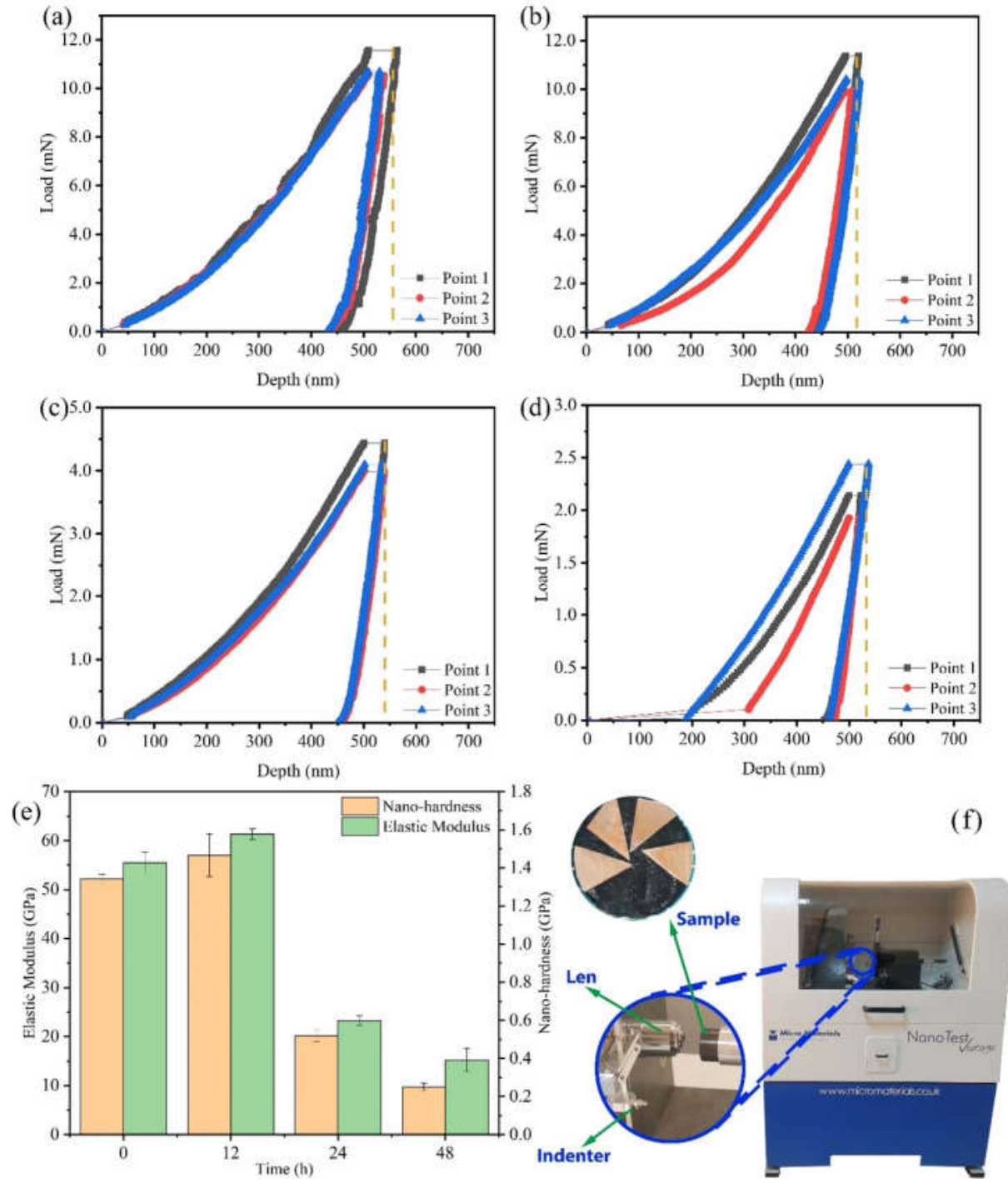

Figure 2. Load-displacement curve of Cu foil treated by DCT for (a) $0 \mathrm{~h}$, (b) $12 \mathrm{~h}$, (c) $24 \mathrm{~h}$, (d) $48 \mathrm{~h}$, and (e) the results of nano-hardness and elastic modulus on the nano-indentation; (f) a picture of the nano-indentation machine.

\subsection{XRD Analysis}

XRD patterns of samples at different DCT time are shown in Figure 4a. The diffraction peak intensity ratio of the $\mathrm{Cu}$ foil was different compared to the standard powder diffraction file (PDF) card. The main peak of the Cu foil was (200) (shown in Figure 4b), instead of (111) in the standard $\mathrm{Cu}$ PDF card due to the intense deformation during the rolling process. The intensities of different diffraction peaks are shown in Figure $4 \mathrm{~b}$. After a DCT process of $12 \mathrm{~h}$, the intensity of (200) and (220) were enhanced while the intensity of (311) was unchanged. The lattice constants were also changed. This phenomenon is also observed in other literatures [31,32]. The lattice paraments of $\mathrm{Cu}$ foils were calculated to be $0.36117 \mathrm{~nm}$, $0.36137 \mathrm{~nm}, 0.36175 \mathrm{~nm}$, and $0.36135 \mathrm{~nm}$ after a DCT time of $0 \mathrm{~h}, 12 \mathrm{~h}, 24 \mathrm{~h}$, and $48 \mathrm{~h}$, respectively. 

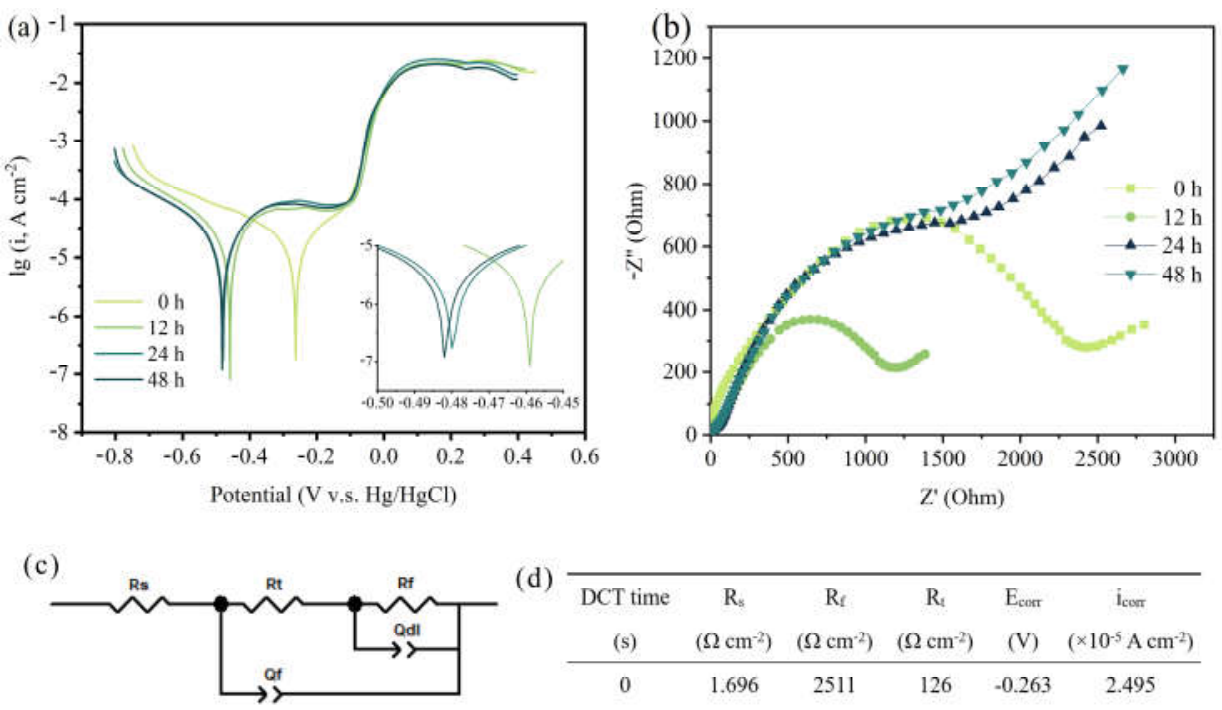

(d)

\begin{tabular}{cccccc}
\hline $\begin{array}{c}\text { DCT time } \\
(\mathrm{s})\end{array}$ & $\begin{array}{c}\mathrm{R}_{\sharp} \\
\left(\Omega \mathrm{cm}^{-2}\right)\end{array}$ & $\begin{array}{c}\mathrm{R}_{\ell} \\
\left(\Omega \mathrm{cm}^{-2}\right)\end{array}$ & $\begin{array}{c}\mathrm{R}_{t} \\
\left(\Omega \mathrm{cm}^{-2}\right)\end{array}$ & $\begin{array}{c}\mathrm{E}_{\text {corr }} \\
(\mathrm{V})\end{array}$ & $\begin{array}{c}\mathrm{i}_{\text {corr }} \\
\left(\times 10^{-5} \mathrm{~A} \mathrm{~cm}^{-2}\right)\end{array}$ \\
\hline 0 & 1.696 & 2511 & 126 & -0.263 & 2.495 \\
12 & 1.522 & 1371 & 43.31 & -0.459 & 2.932 \\
24 & 4.111 & 2649 & 43.95 & -0.480 & 2.096 \\
48 & 4.086 & 3020 & 41.69 & -0.482 & 2.078 \\
\hline
\end{tabular}

Figure 3. Corrosion resistance of (a) potentiodynamic polarization curves in the Tafel region, (b) the EIS curve, (c) the electrical equivalent circuit model, and (d) the corresponding data obtained from the equivalent circuit model.
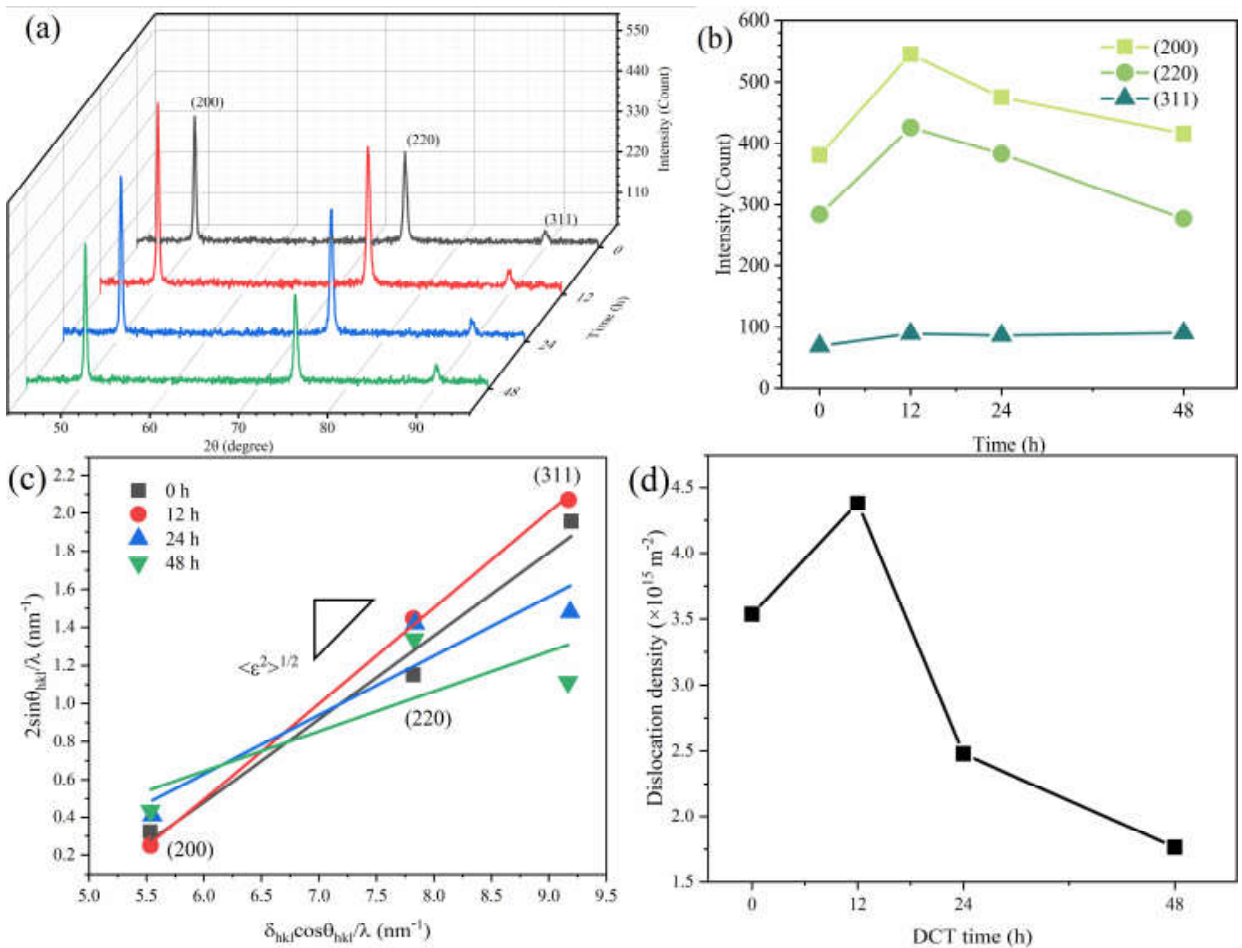

Figure 4. XRD patterns of $\mathrm{Cu}$ foil at various DCT times. $(\mathbf{a}, \mathbf{b})$ the intensities of different diffraction peaks, (c) the relationship between $2 \sin \theta_{h k l} / \lambda$ and $\delta_{h k l} \cos \theta_{h k l} / \lambda$, and (d) the result of dislocation density.

The XRD profiles show no peak shift of the $\mathrm{Cu}$ phase during the DCT process (Figure 4a). However, the full width at half maximum (FWHM) value obtained by the XRD spectrum broadened and then shrank with the increase in DCT time. The diffraction 
peaks (200), (220), and (311) were utilized for analysis. The average microstrain $\left\langle\varepsilon^{2}\right\rangle^{1 / 2}$ was derived from the FWHM value of the XRD peaks using the following $[33,34]$ :

$$
\delta_{e, h k l}=2\left\langle\varepsilon^{2}\right\rangle^{1 / 2} \tan \theta_{h k l}
$$

where $\delta_{e, h k l}$ is the internal stress or lattice distortion, and $\theta_{h k l}$ is the diffraction angle. The size-induced broadening $\delta_{D, h k l}$ can be established by:

$$
\delta_{D, h k l}=\frac{\lambda}{D \cos \theta_{h k l}}
$$

where $\lambda$ is the wavelength $(0.15405 \mathrm{~nm})$, and $D$ is the average grain size. $D$ in the $C u$ foil samples fell in the microscale range, which is large enough to ignore the size effect. Hence, the line broadening $\left(\delta_{h k l}\right)$ can be described as:

$$
\frac{\delta_{h k l} \cos \theta_{h k l}}{\lambda}=2\left\langle\varepsilon^{2}\right\rangle^{1 / 2} \frac{\sin \theta_{h k l}}{\lambda}
$$

Meanwhile, $\delta_{h k l}$ can be expressed by Equation (4),

$$
\delta_{h k l}=\sqrt{\delta_{h k l m}^{2}-\delta_{h k l 0}^{2}}
$$

where $\delta_{h k m l}$ is the FWHM value of the (hkl) diffraction peak of $\mathrm{Cu}$ foil samples, and $\delta_{h k m l}$ is the FWHM value of the (hkl) diffraction peak of standard $\mathrm{Cu}$ [35].

The $\left\langle\varepsilon^{2}\right\rangle^{1 / 2}$ can be obtained from Equation (3) from the linear relationship obtained between $\delta_{h k l} \cos \theta_{h k l} / \lambda$ and $2 \sin \theta_{h k l} / \lambda$, as shown in Figure 4c. The diffraction peaks of (200), (220), and (311) are used to simulate and obtain a slash. The slope of the slash is $\left\langle\varepsilon^{2}\right\rangle^{1 / 2}$. The dislocation density can be described from the $\left\langle\varepsilon^{2}\right\rangle^{1 / 2}$ by following [36,37]:

$$
\rho=\frac{3 \sqrt{2 \pi}\left\langle\varepsilon^{2}\right\rangle^{1 / 2}}{D b}
$$

where $\rho$ is the dislocation density, $D$ is the grain size, and $b$ is the Burgers vector, which can be calculated by Equation (6):

$$
b=\frac{a}{\sqrt{2}}
$$

where $a$ is the lattice parameter of $\mathrm{Cu}$. The dislocation densities calculated by Equations (1)-(6) are shown in Figure 4d.

The dislocation densities significantly increased at a DCT time of $12 \mathrm{~h}$ and then decreased with a further increase in DCT time. The dislocation densities were calculated to be $3.536 \times 10^{15} \mathrm{~m}^{-2}, 4.3798 \times 10^{15} \mathrm{~m}^{-2}, 2.4797 \times 10^{15} \mathrm{~m}^{-2}$, and $1.7640 \times 10^{15} \mathrm{~m}^{-2}$, for DCT-0, DCT-12, DCT-24, and DCT-48 samples, respectively.

The results of the XRD profile show that a long period of the DCT process can reduce the dislocation density, which is beneficial to release the distortion energy and improve the corrosion resistance of $\mathrm{Cu}$ foil. The tensile strength and hardness decrease as the dislocation density decreases. However, within a short period of DCT time ( $12 \mathrm{~h}$ in our experiment), the dislocation density increased significantly. The long-term low-temperature environment stabilizes the base tissue, releases the residual stress in the tissue, and partially misaligns as the structure disappears.

\subsection{EBSD Analysis}

The electron backscatter diffraction (EBSD) measurements were used to show the grain size and morphology of our samples (Figure 5). The inverse pole figure (IPF) obtained by orientation imaging maps (OIM) was used to study the grain orientation. Furthermore, the grain boundary was used to evaluate the grain size and morphology. The $\mathrm{Cu}$ foil had an approximately smooth surface with horizontal stripes produced by the rolling 
deformation, the stripes being distributed along the rolling direction. The distribution of the misorientation angle in Figure 6 shows that the crystallite boundaries were mainly high angle boundaries in nature.
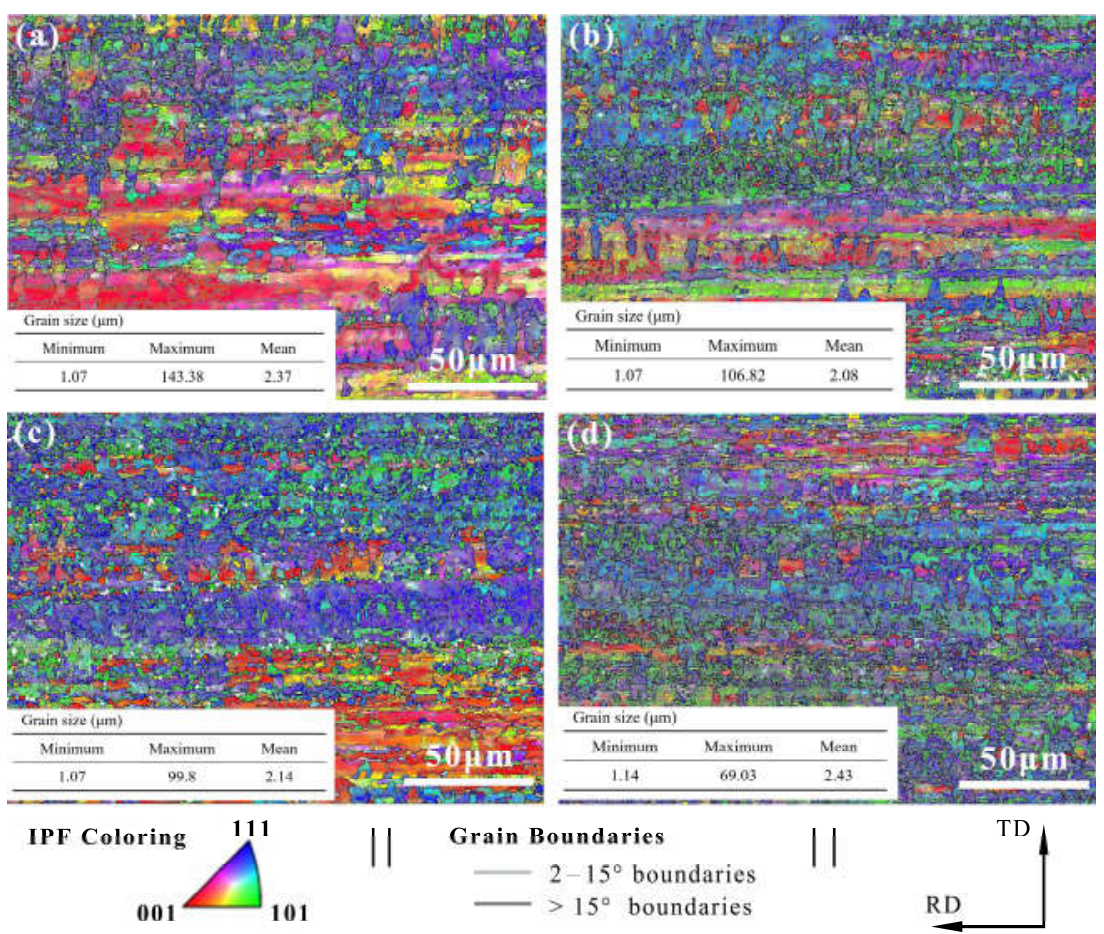

Figure 5. EBSD results at various DCT times of (a) $0 \mathrm{~h}$, (b) $12 \mathrm{~h}$, (c) $24 \mathrm{~h}$, and (d) $24 \mathrm{~h}$.
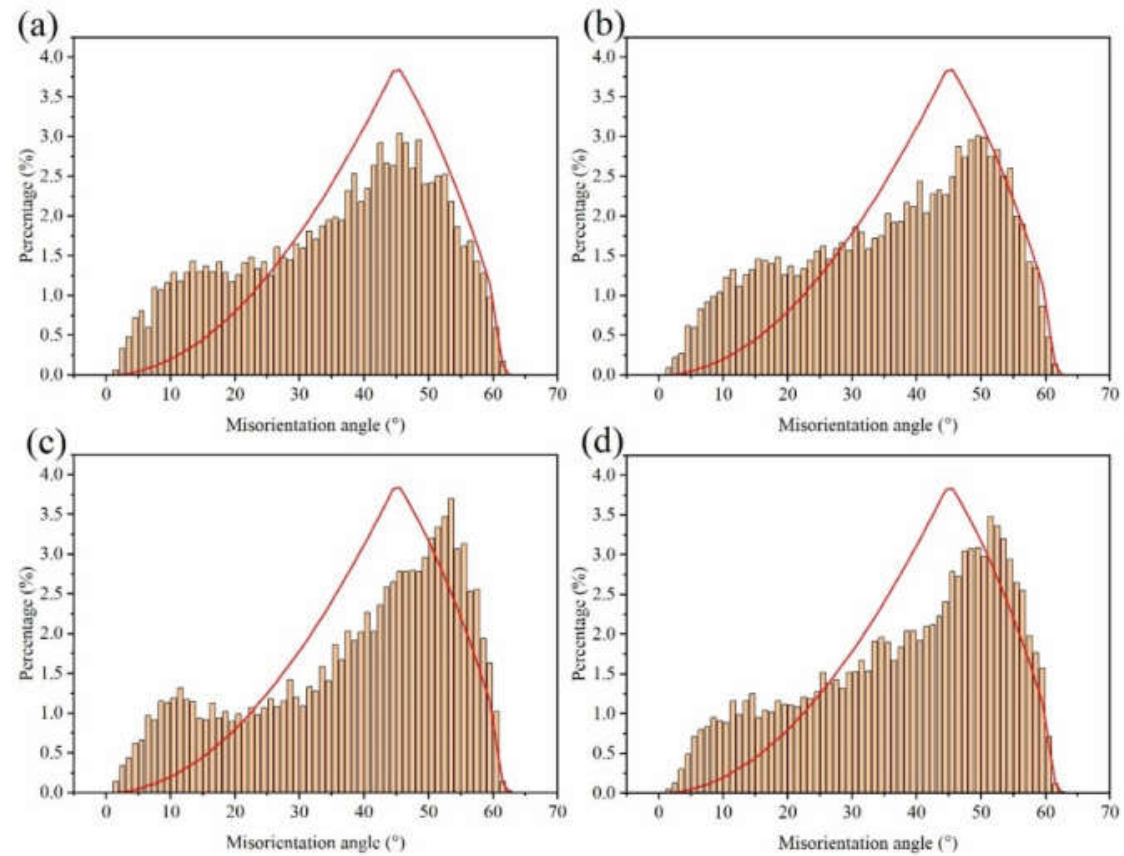

Figure 6. Distribution of the boundary misorientation angle at (a) DCT-0, (b) DCT-12, (c) DCT-24, and (d) DCT-48.

The grain orientation and the frequency of misorientation angle during the DCT process are shown in Table 2. 
Table 2. The results of the recrystallized fraction and the grain orientation fraction.

\begin{tabular}{cccccc}
\hline \multirow{2}{*}{ DCT Time } & \multicolumn{2}{c}{ Grain Boundary Fraction (\%) } & \multicolumn{3}{c}{ Grain Orientation Fraction (\%) } \\
\cline { 2 - 6 } & $\mathbf{2}^{\circ} \mathbf{- 1 5}^{\circ}$ & $\mathbf{> 1 5}^{\circ}$ & $\mathbf{( 0 0 1 )}$ & $\mathbf{( 1 0 1 )}$ & $\mathbf{( 1 1 1 )}$ \\
\hline 0 & 76.7 & 23.3 & 38.5 & 31.5 & 30.0 \\
12 & 74.4 & 25.6 & 16.5 & 41.0 & 42.5 \\
24 & 73.2 & 26.8 & 26.8 & 29.1 & 44.1 \\
48 & 69.8 & 30.2 & 10.8 & 38.7 & 50.5 \\
\hline
\end{tabular}

The lattice plane of (111) gradually increased with the increase in DCT time and showed obvious (111) crystal orientation. Misorientation angles from $2^{\circ}$ to $15^{\circ}$ are defined as low angle grain boundaries (LAGBs), while angles $>15^{\circ}$ are defined as high angle grain boundaries (HAGBs). The LAGBs for $\mathrm{Cu}$ foils under different DCT times are 76.7\%, 74.4\%, $73.2 \%$, and $69.8 \%$, respectively. It can be seen that the frequency of LAGB decreased slowly due to the increase in DCT time, showing that the DCT promotes the transition from LAGBs to HAGBs. The fraction of LAGBs decreased because of the formation of extrinsic dislocation, as shown in Figure 7. LAGBs may have reacted with the extrinsic dislocation, leading to the transformation of LAGBs to HAGBs [38,39]. The $\mathrm{Cu}$ foils experienced thermal shrinkage and volume change when being dropped into the LN2 [32]. Due to shrinkage strain, the stored deformation energy acts as the driving force for the generation and mobility of dislocations, which eventually leads to dislocation interactions [17]. The grain size is depicted in Figure 5. The grain size first decreased then increased with the DCT time, reaching a minimum value of $2.08 \mu \mathrm{m}$ at a DCT time of $12 \mathrm{~h}$.

\subsection{SEM/TEM Observation}

The SEM morphology of the original Cu without DCT processing, and the elements analysis results, are shown in Figure $7 \mathrm{f}$. The $\mathrm{Cu}$ foil had prominent horizontal stripes on its surface due to the rolling process. The element analysis demonstrated that the main component was $\mathrm{Cu}$. The element $\mathrm{Ag}$ was not detected due to the very low concentration of Ag.

To observe the dislocation of the original $\mathrm{Cu}$ foil and the $\mathrm{Cu}$ foil treated by DCT, TEM, high-resolution electron microscopy (HRTEM), and selected-area electron diffraction (SAED) were performed (Figure 7a-e). The dislocation density of the DCT-0 was lower than that of the DCT-12. The sample in the environment of LN2 changed in volume as the temperature dropped to a very low temperature. The image of HRTEM shows the presence of the edge dislocation and that the DCT-12 has more edge dislocation in Figure 7c,d. The compression deformation force produced by the volume changes provided a driving force to promote the formation and migration of dislocation [32,40]. It significantly improved the mechanical performance, as shown in Figures 1 and 2. However, the improvement of the dislocation density reduced the corrosion resistance of the $\mathrm{Cu}$ foil. 

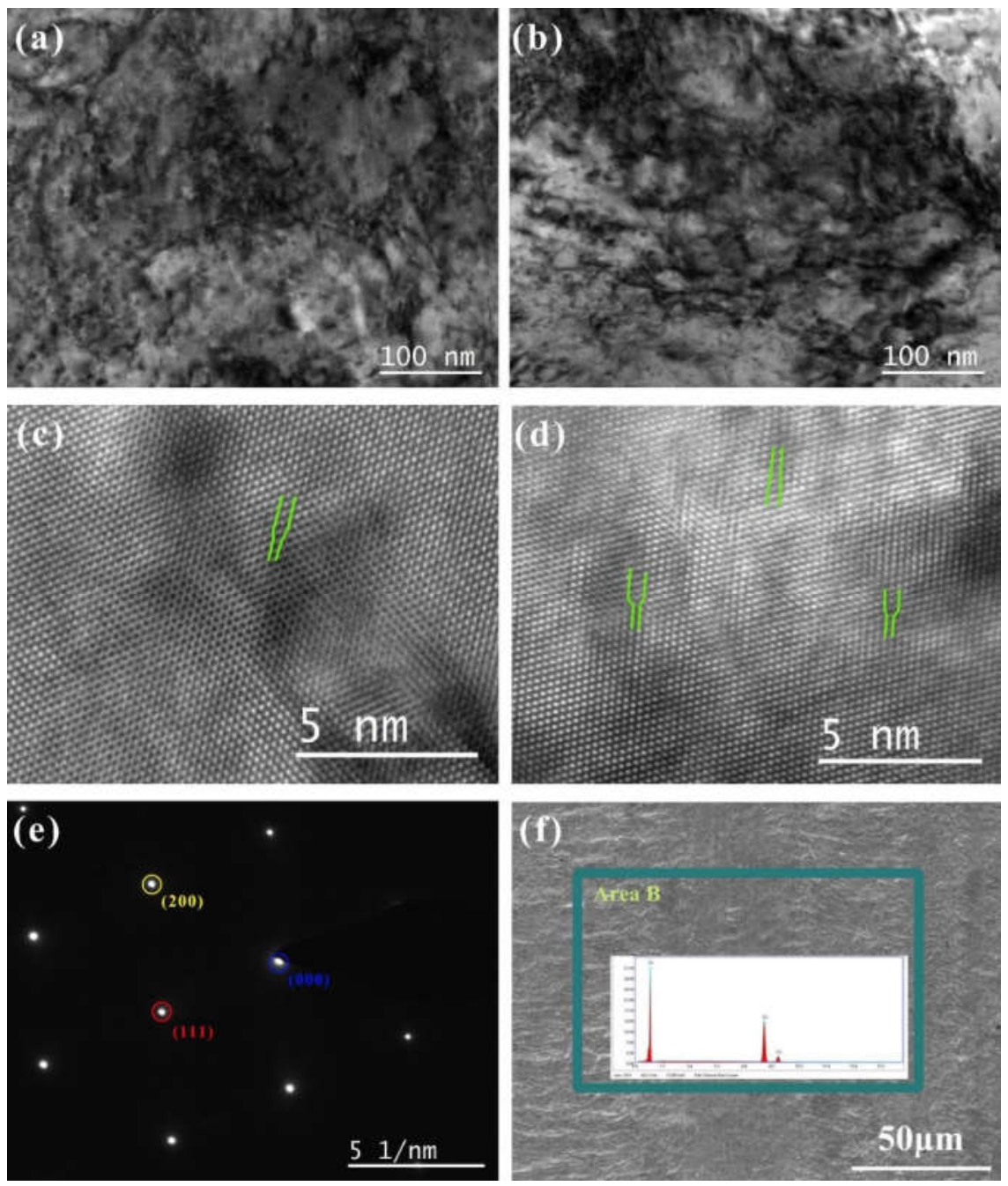

Figure 7. The morphology of TEM and HRTEM of Cu foil at DCT time (a,c) $0 \mathrm{~h}$ and (b,d) $12 \mathrm{~h}$; (e) the SAED spectrum; (f) the SEM morphology of the original $\mathrm{Cu}$ foil and corresponding elements analysis.

\section{Conclusions}

In this work, the effects of DCT time on the microstructure and properties of rolled $\mathrm{Cu}$ foil were investigated. The main conclusions are as follows:

- The DCT can improve the mechanical properties of $\mathrm{Cu}$ foil; the tensile strength and hardness reached a maximum value (394.06 MPa and $1.47 \mathrm{GPa}$, respectively) at a DCT time of $12 \mathrm{~h}$. Corrosion resistance was negatively related to the mechanical properties.

- The grain orientation of (111) was improved with the increase in DCT time. Meanwhile, DCT increased the fraction of HAGBs and the dislocation density. The dislocation density of rolled $\mathrm{Cu}$ foil after a DCT time of $12 \mathrm{~h}$ increased by $19 \%$, which was determined to have a peak value of $4.3798 \times 10^{15} \mathrm{~m}^{-2}$.

- The tensile strength and hardness were related to the grain size and dislocation density. After DCT, LAGBs may react with the extrinsic dislocation, leading to the transformation of LAGBs to HAGBs.

Author Contributions: Conceptualization, Z.D. and X.F.; data curation, X.F.; formal analysis, Z.D.; funding acquisition, B.G.; investigation, X.Z.; methodology, J.N.; project administration, B.G.; resources, Z.D., X.F., J.N., and X.Z.; software, Z.D. and X.F.; supervision, B.G. and X.Z.; validation, B.G. and X.Z.; visualization, J.N.; writing-original draft, Z.D. and X.F.; writing-review and editing, Z.D. and X.F. All authors have read and agreed to the published version of the manuscript. 
Funding: This research was funded by the Major Scientific and Technological Innovation Project of Shandong Province Key R\&D Program, grant number 2019TSLH0101.

Institutional Review Board Statement: Not applicable.

Informed Consent Statement: Not applicable.

Data Availability Statement: The data presented in this study are available on request from the corresponding author.

Conflicts of Interest: The authors declare no conflict of interest. The funders had no role in the design of the study; in the collection, analyses, or interpretation of data; in the writing of the manuscript, or in the decision to publish the results.

\section{References}

1. Li, J.; Zhang, P.; He, H.; Shi, B. Enhanced the thermal conductivity of flexible copper foil by introducing graphene. Mater. Des. 2020, 187, 108373. [CrossRef]

2. Dashairya, L.; Das, D.; Saha, P. Binder-free electrophoretic deposition of $\mathrm{Sb} / \mathrm{rGO}$ on $\mathrm{Cu}$ foil for superior electrochemical performance in Li-ion and Na-ion batteries. Electrochim. Acta 2020, 358, 136948. [CrossRef]

3. Shen, X.; Shao, L.; Tian, Z.; Hu, Z.; Cao, G. Study on the application of carbon-coated copper foil as negative current collector for silicon-based lithium-ion batteries. Int. J. Electrochem. Sci. 2020, 15, 9013-9023. [CrossRef]

4. Jiang, K.; Sandberg, R.B.; Akey, A.J.; Liu, X.; Bell, D.C.; Nørskov, J.K.; Chan, K.; Wang, H. Metal ion cycling of Cu foil for selective $\mathrm{C}-\mathrm{C}$ coupling in electrochemical $\mathrm{CO}_{2}$ reduction. Nat. Catal. 2018, 1, 111-119. [CrossRef]

5. Fei, X.; Dong, Z.; Gong, B.; Zhao, X. Lightweight Through-Hole Copper Foil as a Current Collector for Lithium-Ion Batteries. ACS Appl. Mater. Interfaces 2021, 13, 42266-42275. [CrossRef] [PubMed]

6. Choi, Y.-M.; Jung, J.; Lee, A.S.; Hwang, S.S. Photosensitive hybrid polysilsesquioxanes for etching-free processing of flexible copper clad laminate. Compos. Sci. Technol. 2021, 201, 108556. [CrossRef]

7. Wang, Y.; Qing, F.; Jia, Y.; Duan, Y.; Shen, C.; Hou, Y.; Niu, Y.; Shi, H.; Li, X. Synthesis of large-area graphene films on rolled-up Cu foils by a "breathing" method. Chem. Eng. J. 2021, 405, 127014. [CrossRef]

8. Lai, H.; Chen, T.; Yang, G.; Zhang, Y.; Cu, C. The Influence of Pre-layer Processing on the Signal Integrity of 5G High Frequency Communication Multilayer LCP Lines. In Proceedings of the 2021 5th IEEE Electron Devices Technology \& Manufacturing Conference (EDTM), Chengdu, China, 8-11 April 2021; pp. 1-3.

9. Lee, C.; Kim, S.; Jo, M.; Lee, J. Residual Interfacial Deformation in Flexible Copper Clad Laminate Occurring During Roll-to-Roll Composite Film Manufacturing. Int. J. Precis. Eng. Manuf. Technol. 2021, 8, 805-815. [CrossRef]

10. Natarajan, S.; Aravindan, V. An Urgent Call to Spent LIB Recycling: Whys and Wherefores for Graphite Recovery. Adv. Energy Mater. 2020, 10, 1-8. [CrossRef]

11. Zhang, Q.; Chen, H.; Luo, L.; Zhao, B.; Luo, H.; Han, X.; Wang, J.; Wang, C.; Yang, Y.; Zhu, T.; et al. Harnessing the concurrent reaction dynamics in active $\mathrm{Si}$ and $\mathrm{Ge}$ to achieve high performance lithium-ion batteries. Energy Environ. Sci. 2018, 11, 669-681. [CrossRef]

12. Xia, T.; Liang, T.; Xiao, Z.; Chen, J.; Liu, J.; Zhong, S. Nanograined copper foil as a high-performance collector for lithium-ion batteries. J. Alloys Compd. 2020, 831, 154801. [CrossRef]

13. Xiao, Z.; Chen, J.; Liu, J.; Liang, T.; Xu, Y.; Zhu, C.; Zhong, S. Microcrystalline copper foil as a high performance collector for lithium-ion batteries. J. Power Sources 2019, 438, 226973. [CrossRef]

14. Song, G.; Wang, Q.; Sun, L.; Li, S.; Sun, Y.; Fu, Q.; Pan, C. One-step synthesis of sandwich-type Cu/graphene/Cu ultrathin foil with enhanced property via electrochemical route. Mater. Des. 2020, 191, 108629. [CrossRef]

15. Bansal, A.; Singla, A.K.; Dwivedi, V.; Goyal, D.K.; Singla, J.; Gupta, M.K.; Krolczyk, G.M. Influence of cryogenic treatment on mechanical performance of friction stir Al-Zn-Cu alloy weldments. J. Manuf. Process. 2020, 56, 43-53. [CrossRef]

16. Singla, A.K.; Singh, J.; Sharma, V.S. Impact of Cryogenic Treatment on Mechanical Behavior and Microstructure of Ti-6Al-4V ELI Biomaterial. J. Mater. Eng. Perform. 2019, 28, 5931-5945. [CrossRef]

17. Liu, K.; Chen, X.; Shen, Q.; Pan, Z.; Singh, R.A.; Jayalakshmi, S.; Konovalov, S. Microstructural evolution and mechanical properties of deep cryogenic treated $\mathrm{Cu}-\mathrm{Al}-\mathrm{Si}$ alloy fabricated by Cold Metal Transfer (CMT) process. Mater. Charact. 2020, 159, 110011. [CrossRef]

18. Jovičević-Klug, P.; Jenko, M.; Jovičević-Klug, M.; Šetina Batič, B.; Kovač, J.; Podgornik, B. Effect of deep cryogenic treatment on surface chemistry and microstructure of selected high-speed steels. Appl. Surf. Sci. 2021, 548, 149257. [CrossRef]

19. Dong, F.; Yi, Y.; Huang, C.; Huang, S. Influence of cryogenic deformation on second-phase particles, grain structure, and mechanical properties of Al-Cu-Mn alloy. J. Alloys Compd. 2020, 827, 154300. [CrossRef]

20. Funk, P.A.; Kanaan, A.; Shank, C.; Cooke, P.; Sevostianov, I.; Thomas, J.W.; Pate, M.O. Quantifying deep cryogenic treatment extent and its effect on steel properties. Int. J. Eng. Sci. 2021, 167, 103521. [CrossRef]

21. Li, X.B.; Jiang, G.M.; Di, J.P.; Yang, Y.; Wang, C.L. Effect of cryogenic rolling on the microstructural evolution and mechanical properties of pure copper sheet. Mater. Sci. Eng. A 2020, 772, 138811. [CrossRef] 
22. Lv, J.W.; Wang, F.L.; Yin, D.W.; Zhang, S.; Cai, Z.Q.; Shi, Z.L.; Ma, M.Z.; Zhang, X.Y. Effect of deep cryogenic cycling treatment on the microstructure and mechanical properties of Ti-based bulk metallic glass. J. Alloys Compd. 2021, 887, 161386. [CrossRef]

23. He, G.; Zhang, Z.F.; Löser, W.; Eckert, J.; Schultz, L. Effect of Ta on glass formation, thermal stability and mechanical properties of a $\mathrm{Zr}_{52.25} \mathrm{Cu}_{28.5} \mathrm{Ni}_{4.75} \mathrm{Al}_{9.5} \mathrm{Ta}_{5}$ bulk metallic glass. Acta Mater. 2003, 51, 2383-2395. [CrossRef]

24. Yuan, S.; Cheng, W.; Liu, W.; Xu, Y. A novel deep drawing process for aluminum alloy sheets at cryogenic temperatures. J. Mater. Process. Technol. 2020, 284, 116743. [CrossRef]

25. Barylski, A.; Aniołek, K.; Dercz, G.; Kupka, M.; Kaptacz, S. The effect of deep cryogenic treatment and precipitation hardening on the structure, micromechanical properties and wear of the Mg-Y-Nd-Zr alloy. Wear 2021, 468-469, 203587. [CrossRef]

26. Kim, B.; Chang, I.S.; Dinsdale, R.M.; Guwy, A.J. Accurate measurement of internal resistance in microbial fuel cells by improved scanning electrochemical impedance spectroscopy. Electrochim. Acta 2021, 366, 137388. [CrossRef]

27. Kosakian, A.; Secanell, M. Estimating charge-transport properties of fuel-cell and electrolyzer catalyst layers via electrochemical impedance spectroscopy. Electrochim. Acta 2021, 367, 137521. [CrossRef]

28. Shin, D.Y.; Ahn, H.J. Interfacial Engineering of a Heteroatom-Doped Graphene Layer on Patterned Aluminum Foil for Ultrafast Lithium Storage Kinetics. ACS Appl. Mater. Interfaces 2020, 12, 19210-19217. [CrossRef]

29. Huttunen-Saarivirta, E.; Rajala, P.; Bomberg, M.; Carpén, L. EIS study on aerobic corrosion of copper in ground water: Influence of micro-organisms. Electrochim. Acta 2017, 240, 163-174. [CrossRef]

30. Shang, F.; Chen, S.; Zhou, L.; Jia, W.; Cui, T.; Liang, J.; Liu, C.; Wang, M. Effect of laser energy volume density on wear resistance and corrosion resistance of 30Cr15MoY alloy steel coating prepared by laser direct metal deposition. Surf. Coat. Technol. 2021, 421, 127382. [CrossRef]

31. Zhang, X.; Wu, G.; Liu, W.; Ding, W. Low temperature mechanical properties of as-extruded Mg-10Gd-3Y-0.5Zr magnesium alloy. Trans. Nonferrous Met. Soc. China 2012, 22, 2883-2890. [CrossRef]

32. Liu, J.; Li, G.; Chen, D.; Chen, Z. Effect of Cryogenic Treatment on Deformation Behavior of As-cast AZ91 Mg Alloy. Chinese J. Aeronaut. 2012, 25, 931-936. [CrossRef]

33. Cheng, H.; Wang, H.Y.; Xie, Y.C.; Tang, Q.H.; Dai, P.Q. Controllable fabrication of a carbide-containing FeCoCrNiMn high-entropy alloy: Microstructure and mechanical properties. Mater. Sci. Technol. 2017, 33, 2032-2039. [CrossRef]

34. Xie, M.; Huang, W.; Chen, H.; Gong, L.; Xie, W.; Wang, H.; Yang, B. Microstructural evolution and strengthening mechanisms in cold-rolled Cu-Ag alloys. J. Alloys Compd. 2021, 851, 156893. [CrossRef]

35. Deng, L.; Han, K.; Wang, B.; Yang, X.; Liu, Q. Thermal stability of Cu-Nb microcomposite wires. Acta Mater. 2015, 101, 181-188. [CrossRef]

36. Zhang, X.K.; Yang, X.Y.; Chen, W.; Qin, J.; Fouse, J.P. Effect of stacking fault energy on mechanical properties and annealing behavior of brasses. J. Alloys Compd. 2016, 679, 400-407. [CrossRef]

37. Williamson, G.K.; Smallman, R.E., III. Dislocation densities in some annealed and cold-worked metals from measurements on the X-ray debye-scherrer spectrum. Philos. Mag. A J. Theor. Exp. Appl. Phys. 1956, 1, 34-46. [CrossRef]

38. Xue, P.; Xiao, B.L.; Ma, Z.Y. High tensile ductility via enhanced strain hardening in ultrafine-grained Cu. Mater. Sci. Eng. A 2012, 532, 106-110. [CrossRef]

39. Zhao, Y.H.; Bingert, J.F.; Zhu, Y.T.; Liao, X.Z.; Valiev, R.Z.; Horita, Z.; Langdon, T.G.; Zhou, Y.Z.; Lavernia, E.J. Tougher ultrafine grain $\mathrm{Cu}$ via high-angle grain boundaries and low dislocation density. Appl. Phys. Lett. 2008, 92, 81903. [CrossRef]

40. Yuan, C.; Wang, Y.; Sang, D.; Li, Y.; Jing, L.; Fu, R.; Zhang, X. Effects of deep cryogenic treatment on the microstructure and mechanical properties of commercial pure zirconium. J. Alloys Compd. 2015, 619, 513-519. [CrossRef] 